\title{
An analysis from the Quality Outcomes Database, Part 2. Predictive model for return to work after elective surgery for lumbar degenerative disease
}

\author{
Anthony L. Asher, MD, ${ }^{1}$ Clinton J. Devin, MD, ${ }^{2}$ Kristin R. Archer, PhD, DPT, ${ }^{3,4}$ Silky Chotai, MD, ${ }^{2}$ \\ Scott L. Parker, MD, ${ }^{2}$ Mohamad Bydon, MD, ${ }^{5}$ Hui Nian, PhD, ${ }^{6}$ Frank E. Harrell Jr., PhD, ${ }^{6}$ \\ Theodore Speroff, PhD, ${ }^{7,8}$ Robert S. Dittus, MD, MPH, ${ }^{7,8}$ Sharon E. Philips, MS, ${ }^{6}$ \\ Christopher I. Shaffrey, MD, ${ }^{9}$ Kevin T. Foley, MD, ${ }^{10}$ and Matthew J. McGirt, MD, ${ }^{1}$ \\ for QOD Vanguard Sites
}

\begin{abstract}
1Department of Neurological Surgery, Carolina Neurosurgery and Spine Associates, and Neurological Institute, Carolinas Healthcare System, Charlotte, North Carolina; ${ }^{2}$ Department of Orthopedic Surgery and Neurological Surgery, Vanderbilt Spine Center, ${ }^{3}$ Department of Orthopedic Surgery, Vanderbilt Spine Center, and ${ }^{4}$ Department of Physical Medicine and Rehabilitation, Vanderbilt University Medical Center, Nashville, Tennessee; ${ }^{5}$ Department of Neurological Surgery, Mayo Clinic, Rochester, Minnesota; ${ }^{6}$ Department of Biostatistics, Vanderbilt University School of Medicine, Nashville, Tennessee; ${ }^{7}$ Geriatric Research Education Clinical Center, Tennessee Valley Health System, Veterans Health Administration, Nashville, Tennessee; ${ }^{8}$ Departments of Medicine and Biostatistics, Division of General Internal Medicine and Public Health, Center for Health Services Research, Vanderbilt University School of Medicine, Nashville, Tennessee; ${ }^{2}$ Department of Neurosurgery, University of Virginia Medical Center, Charlottesville, Virginia; and ${ }^{10}$ Department of Neurosurgery, University of Tennessee Health Sciences Center, Semmes-Murphey Neurologic \& Spine Institute, Memphis, Tennessee
\end{abstract}

OBJECTIVE Current costs associated with spine care are unsustainable. Productivity loss and time away from work for patients who were once gainfully employed contributes greatly to the financial burden experienced by individuals and, more broadly, society. Therefore, it is vital to identify the factors associated with return to work (RTW) after lumbar spine surgery. In this analysis, the authors used data from a national prospective outcomes registry to create a predictive model of patients' ability to RTW after undergoing lumbar spine surgery for degenerative spine disease.

METHODS Data from 4694 patients who underwent elective spine surgery for degenerative lumbar disease, who had been employed preoperatively, and who had completed a 3-month follow-up evaluation, were entered into a prospective, multicenter registry. Patient-reported outcomes-Oswestry Disability Index (ODI), numeric rating scale (NRS) for back pain (BP) and leg pain (LP), and EQ-5D scores-were recorded at baseline and at 3 months postoperatively. The time to RTW was defined as the period between operation and date of returning to work. A multivariable Cox proportional hazards regression model, including an array of preoperative factors, was fitted for RTW. The model performance was measured using the concordance index (c-index).

RESULTS Eighty-two percent of patients $(n=3855)$ returned to work within 3 months postoperatively. The risk-adjusted predictors of a lower likelihood of RTW were being preoperatively employed but not working at the time of presentation, manual labor as an occupation, worker's compensation, liability insurance for disability, higher preoperative ODI score, higher preoperative NRS-BP score, and demographic factors such as female sex, African American race, history of diabetes, and higher American Society of Anesthesiologists score. The likelihood of a RTW within 3 months was higher in patients with higher education level than in those with less than high school-level education. The c-index of the model's performance was 0.71 . 
CONCLUSIONS This study presents a novel predictive model for the probability of returning to work after lumbar spine surgery. Spine care providers can use this model to educate patients and encourage them in shared decision-making regarding the RTW outcome. This evidence-based decision support will result in better communication between patients and clinicians and improve postoperative recovery expectations, which will ultimately increase the likelihood of a positive RTW trajectory.

https://thejns.org/doi/abs/10.3171/2016.8.SPINE16527

KEY WORDS QOD; Quality Outcomes Database; patient-reported outcomes; return to work; RTW; lumbar; surgery; degenerative

$\mathrm{L}$ ow-back pain associated with degenerative spine disease is the leading and most costly cause of work-related disability in the US..$^{22,45,60,66,67}$ Among those gainfully employed, approximately 26 million individuals report frequent low-back pain, and of that number $8 \%$ become disabled in any given year; this annual disability is responsible for $40 \%$ of all lost workdays. ${ }^{20,26,30}$ This disability results in an estimated $\$ 30$ billion in direct medical costs due to back-related health care resource utilization ${ }^{42,63}$ and up to $\$ 20$ billion annually in indirect costs due to lost productivity. ${ }^{2}$

A considerable number of patients require surgery for lumbar degenerative conditions to restore functional and work-related capacity. ${ }^{1,17,62,67}$ Several prospective and randomized controlled trials have shown the efficacy of surgical treatment, ${ }^{1,17,65,67}$ but other studies have demonstrated that up to $25 \%$ of patients experience minimal improvement in quality of life (QOL) ${ }^{46,58,52}$ and up to $10 \%$ experience a major complication or require hospital readmission after surgery. ${ }^{10,14,25,38}$ Return to work (RTW) is an important functional outcome measure. ${ }^{28}$ The time away from work and the individual's diminished work capacity after spine surgery create a significant individual and societal financial burden. ${ }^{11,15,55,60,63}$ Studies have demonstrated wide variability in disability and RTW rates following lumbar spine surgery, with permanent or temporary disability ranging from $18 \%$ to $68 \%$ and a RTW rate ranging from $41 \%$ to $81 \% .{ }^{24,29,43,51,54}$ Therefore, identifying the preoperative factors associated with RTW will help employers, payers, and providers understand the variability in RTW outcomes.

In the current era of patient-centered care, engaging patients in shared decision-making in their treatment planning is of utmost importance. Shared decision-making is defined as a process "involving the patient and provider, both parties participating in the treatment decision-making process, requiring information sharing, and both parties agreeing to the treatment decision made."13,19 The concept of informed, shared decision-making was first popularized in a report issued by the President's Commission for the Study of Ethical Problems in Medicine and Biomedical and Behavioral Research in 1982. ${ }^{19}$ True informed decision-making is only achievable if patients are provided with the factual probability of outcomes based on their individual risk factors. The ability to predict RTW, based on preoperative patient-specific and surgeryspecific factors, will allow surgeons to have substantive personalized discussion with patients. This will promote realistic expectations among patients, family members, payers, and employers regarding RTW after surgery. ${ }^{35}$
However, to date, a validated prediction model capable of providing individualized estimations of RTW following elective lumbar spine surgery has yet to be introduced. Utilizing the Quality Outcomes Database (QOD), we aimed to create a clinically relevant predictive model for RTW following elective lumbar spine surgery for degenerative spine pathologies.

\section{Methods \\ The QOD Registry}

Data from patients undergoing elective spine surgery for degenerative lumbar disease were entered into the prospective multicenter QOD registry over a 2-year period. QOD is designed to establish risk-adjusted expected morbidity rates for the most common lumbar surgical procedures performed by spine surgeons. ${ }^{5,7}$ The QOD registry enrolls spine surgery patients from 74 participating centers across 26 US states via representative sampling and collects measures of surgical safety and patient-reported outcomes (PROs). A detailed account of QOD enrollment methodologies has been outlined in previous publications. ${ }^{6,7}$

\section{Inclusion and Exclusion Criteria}

Patients undergoing lumbar surgery performed for primary stenosis, spondylolisthesis, disc herniation, symptomatic mechanical disc collapse, and revision surgery, including recurrent same-level disc herniation and adjacent-segment disease, were eligible for inclusion. Reasons for exclusion included spinal infection, tumor, fracture, traumatic dislocation, deformity, pseudarthrosis, recurrent multilevel stenosis, and neurological paralysis due to preexisting spinal disease or injury, age less than 18 years, and incarceration.

\section{Demographic Variables}

We recorded the following patient demographic variables when reviewing electronic medical records from the QOD registry: age, gender, body mass index (BMI), American Society of Anesthesiologists (ASA) grade, history of surgery, history of diabetes, coronary artery disease (CAD), osteoporosis, dominant presenting symptom, presence of motor deficit on examination, symptom duration, diagnosis, preoperative ambulatory status, and surgery-specific variables including approach (anterior or posterior), number of levels involved, need for fusion, and presence/absence of an interbody graft. Patient-reported variables, recorded via patient interview and confirmed 
through the electronic medical records, were as follows: race, smoking status, anxiety, depression, education, employment status, preoperative employment but not working at the time of surgery (employed patients were further dichotomized as either employed and working at the time of surgery, or employed but not working at the time of surgery), type of occupation (sedentary job, light manual labor job, medium labor, and heavy labor job), workers' compensation, liability insurance, and health insurance status (uninsured, private insurance, uninsured, Medicare, Medicaid, or Veterans Affairs/government).

\section{Interviews and PRO Questionnaires}

Baseline (preoperative) and 3-month assessments were conducted either through phone interviews conducted by a data coordinator not involved with clinical care or through self-administration, either during clinic visit or by mail.7,48 Interviewers gathered data on employment status and on disability, pain, and QOL. Patients who were employed preoperatively were asked at 3 months whether "they were able to RTW after surgery?" If they responded "yes," they were asked to specify "the date of returning to work" at the 3-month follow-up interview, and the time to RTW was defined as the period spanning the date of the operation and the date on which patients returned to work. Patients responding "no" were considered right-censored on the day of interview. Validated PRO questionnaires were used to collect data on additional outcome measures: 1) disease-specific physical disability (established using the Oswestry Disability Index [ODI]);22,23 2) preference-based QOL status, established using the EQ-5D instrument; ${ }^{21}$ and 3) pain, established using the numeric rating scale (NRS) for back pain (BP) and leg pain (LP). ${ }^{41}$ The outcome scores were then entered into a national aggregate database through a secure password-protected web-based portal (Research Electronic Data Capture). ${ }^{33}$ At the time of analysis, 48 of 74 total sites had crossed the 3-month patient follow-up timeline and were included in the analysis.

\section{Statistical Analysis}

Analysis of prospectively collected data was conducted. Medians and interquartile ranges (IQRs) for continuous variables and frequencies for categorical variables were computed for patient-specific and surgery-specific variables. A multivariable Cox proportional hazards regression model was fitted on an array of patient-specific factors for time to RTW. The variables included in the model were age; gender; race; smoking status; employment; occupation type; number of spinal levels; ASA grade; BMI; diabetes; osteoporosis; CAD; education level; anxiety; depression; dominant symptom; motor deficit; symptom duration; principal spinal diagnosis; workers' compensation; liability insurance for disability; insurance type; ambulatory status; lumbar fusion, anterior, posterior or combined approach; and preoperative ODI, EQ-5D, and NRS-BP/LP scores. We assumed a linear relationship for the surgical level operated on (Level 1-4), and a smooth relationship for other continuous variables using restricted cubic regression splines with 4 knots for age and BMI and 3 knots for preoperative disability, QOL, and pain scores (the location of knots was chosen based on the upper and lower quartiles for that variable). All the other predictors were included as binary or categorical variables. The effects of predictors on the likelihood of patients returning to work were reported as the hazard ratio (HR) and the corresponding confidence interval (CI) was calculated using Wald statistics. The HRs for the continuous variables in the model were computed using the upper and lower quartile values; $p$ values represent the overall effect over the whole range of the continuous variable. The importance of the individual predictor to the RTW outcome was computed using the following formula: Wald chi-square value minus predictor degree of freedom.

The higher the difference, the higher is the importance of that predictor in the model. The calibration and discrimination of the model was internally validated using the bootstrap resampling to estimate the likely performance of the model on a new sample of patients. The model performance was measured by concordance index (c-index). A c-index of 0.5 is considered a random predication and value of 1 suggests that the model is perfectly discriminating. ${ }^{31,32} \mathrm{~A} 2$-sided $p$ value less $<0.05$ was considered statistically significant. The analysis was performed using the $\mathrm{R}$ statistical program (version 3.1.2, www.r-project.org).

\section{Results}

Of a total of 14,985 patients undergoing elective spine surgery for degenerative lumbar disease, 6895 patients (46\%) were preoperatively employed and had plans to RTW after surgery. Of those, 5147 patients (75\%) completed a 3-month interview, and the 4694 patients (68\%) who provided information on RTW form the basis of the current analyses. Eighty-two percent of patients $(n=3855)$ returned to work within 3 months of surgery.

\section{Patient Demographics and Surgical Characteristics}

The median age of the 4694 patients in the study cohort was 52 years (IQR 41-60 years), and 2768 (59\%) were male. Nineteen percent $(n=877)$ of patients were current smokers, and $12 \%(n=545)$ had diabetes at the time of surgery. Median BMI of the cohort was 29.4 (IQR 25.8-34). Thirty-six percent of patients $(\mathrm{n}=1696)$ had leg-dominant symptoms, $18 \%(n=839)$ had back-dominant symptoms, and $46 \%$ of patients $(n=2159)$ had both leg- and back-dominant symptoms. Ninety-three percent of patients $(n=4123)$ were ambulatory at the time of surgery, and $6 \%(\mathrm{n}=283)$ were ambulatory with an assistive device. With regards to diagnosis, 52\% $(\mathrm{n}=2437)$ had a disc herniation, $23 \%(\mathrm{n}=1062)$ lumbar stenosis, $15 \%(\mathrm{n}$ $=720)$ lumbar spondylolisthesis, $7 \%(\mathrm{n}=339)$ recurrent disc herniation, $2 \%(\mathrm{n}=96)$ adjacent-segment disease, and $0.6 \%(\mathrm{n}=30)$ had symptomatic mechanical disc collapse. A history of lumbar surgery was noted in $8 \%(\mathrm{n}=389)$ of patients. Twenty-six percent of patients $(n=1232)$ underwent lumbar fusion surgery. Tables 1 and 2 summarize the patient-specific and surgery-specific variables included in the model for RTW.

\section{Predictive Model for RTW}

In a multivariable Cox proportional hazards regression 
TABLE 1. Characteristics of patients in the study cohort

\begin{tabular}{|c|c|}
\hline Variable & Value \\
\hline No. of patients & 4694 \\
\hline Median age in yrs & $52(41-60) \dagger$ \\
\hline$\%$ male sex & $59(2768)$ \\
\hline Median BMI & $29.4(25.8-34) \dagger$ \\
\hline Hispanic & $3 \%(121)$ \\
\hline \multicolumn{2}{|l|}{ Race } \\
\hline White & $91 \%(4246)$ \\
\hline African American & $6 \%(302)$ \\
\hline Other & $3 \%(146)$ \\
\hline \multicolumn{2}{|l|}{ Education } \\
\hline$<$ High school & $2 \%(99)$ \\
\hline High school diploma & $39 \%(1791)$ \\
\hline 2-yr college degree & $19 \%(887)$ \\
\hline 4-yr college degree & $24 \%(1127)$ \\
\hline Post-college & $16 \%(748)$ \\
\hline Past surgery & $8 \%(389)$ \\
\hline Smoker & $19 \%(877)$ \\
\hline Diabetes & $12 \%(545)$ \\
\hline CAD & $6 \%(269)$ \\
\hline Osteoporosis & $2 \%(87)$ \\
\hline Anxiety & $18 \%(726)$ \\
\hline Depression & $18 \%(726)$ \\
\hline \multicolumn{2}{|l|}{ Dominant symptom } \\
\hline Back dominant & $18 \%(839)$ \\
\hline Leg dominant & $36 \%(1696)$ \\
\hline Back $=$ leg $^{*}$ & $46 \%(2159)$ \\
\hline Motor deficit & $27 \%(1244)$ \\
\hline \multicolumn{2}{|l|}{ Symptom duration } \\
\hline$<3 \mathrm{mos}$ & $16 \%(757)$ \\
\hline$>3 \mathrm{mos}$ & $84 \%(3884)$ \\
\hline \multicolumn{2}{|l|}{ Diagnosis } \\
\hline Disc herniation & $52 \%(2437)$ \\
\hline Recurrent disc herniation & $7 \%(339)$ \\
\hline Spondylolisthesis & $15 \%(720)$ \\
\hline Stenosis & $23 \%(1062)$ \\
\hline Adjacent-segment disease & $2 \%(96)$ \\
\hline Symptomatic mechanical disc collapse & $0.6 \%(30)$ \\
\hline \multicolumn{2}{|l|}{ Ambulation } \\
\hline Independent & $93 \%(4123)$ \\
\hline With an assist device & $6 \%(283)$ \\
\hline Wheelchair bound (nonambulatory) & $0.5 \%(23)$ \\
\hline \multicolumn{2}{|l|}{ Occupation } \\
\hline Sedentary & $33 \%(1554)$ \\
\hline Light & $24 \%(1130)$ \\
\hline Medium & $23 \%(1083)$ \\
\hline Heavy & $20 \%(927)$ \\
\hline Workers' compensation & $4 \%(204)$ \\
\hline Liability & $4 \%(204)$ \\
\hline
\end{tabular}

CONTINUED IN NEXT COLUMN
» CONTINUED FROM PREVIOUS COLUMN

TABLE 1. Characteristics of patients in the study cohort

\begin{tabular}{lc}
\hline \multicolumn{1}{c}{ Variable } & Value \\
\hline Insurance status & \\
\hline Uninsured & $0.9 \%(40)$ \\
\hline Medicare & $8 \%(371)$ \\
\hline Medicaid & $2 \%(99)$ \\
\hline Veterans Affairs/government & $3 \%(120)$ \\
\hline Private & $87 \%(4058)$ \\
\hline PROs & $46(36-56) \dagger$ \\
\hline ODI score & $0.60(0.38-0.77) \dagger$ \\
\hline EQ-5D score & $7(4-8) \dagger$ \\
\hline NRS-BP score & $7(5-9) \dagger$ \\
\hline NRS-LP score
\end{tabular}

* Indicates pain is both leg and back dominant.

$\dagger$ Values presented as the median (IQR).

model, after adjusting for patient- and surgery-specific variables (Fig. 1), the likelihood of returning to work at 3 months after surgery was significantly higher in patients with a higher education level ( $\mathrm{p}<0.001$, for patients with postcollege degree vs less than high school education).

The likelihood of returning to work was significantly lower in female versus male patients $(\mathrm{p}<0.001)$, African American versus white patients $(\mathrm{p}<0.001)$, patients with diabetes versus those without a history of diabetes $(\mathrm{p}=0.0069)$, and those with preoperative symptom duration greater than 3 months versus less than 3 months $(\mathrm{p}=0.0007)$. With regard to diagnosis, the probability of returning to work within 3 months of surgery did not differ for the diagnosis of stenosis, recurrent disc herniation,

TABLE 2. Surgical variables included in the model

\begin{tabular}{cc}
\hline \multicolumn{1}{c}{ Variable } & $\%$ (value) \\
\hline No. of patients & 4694 \\
\hline ASA score & $13(588)$ \\
\hline 1 & $65(3018)$ \\
\hline 2 & $23(1059)$ \\
\hline $3 / 4$ & \\
\hline No. of fused levels & $42(1837)$ \\
\hline 1 & $46(2022)$ \\
\hline 2 & $10(440)$ \\
\hline 3 & $3(113)$ \\
\hline 4 & $98(4540)$ \\
\hline Approach & $2(80)$ \\
\hline Posterior & $74(3456)$ \\
\hline Anterior & $4(204)$ \\
\hline Fusion & $22(1028)$ \\
\hline No
\end{tabular}




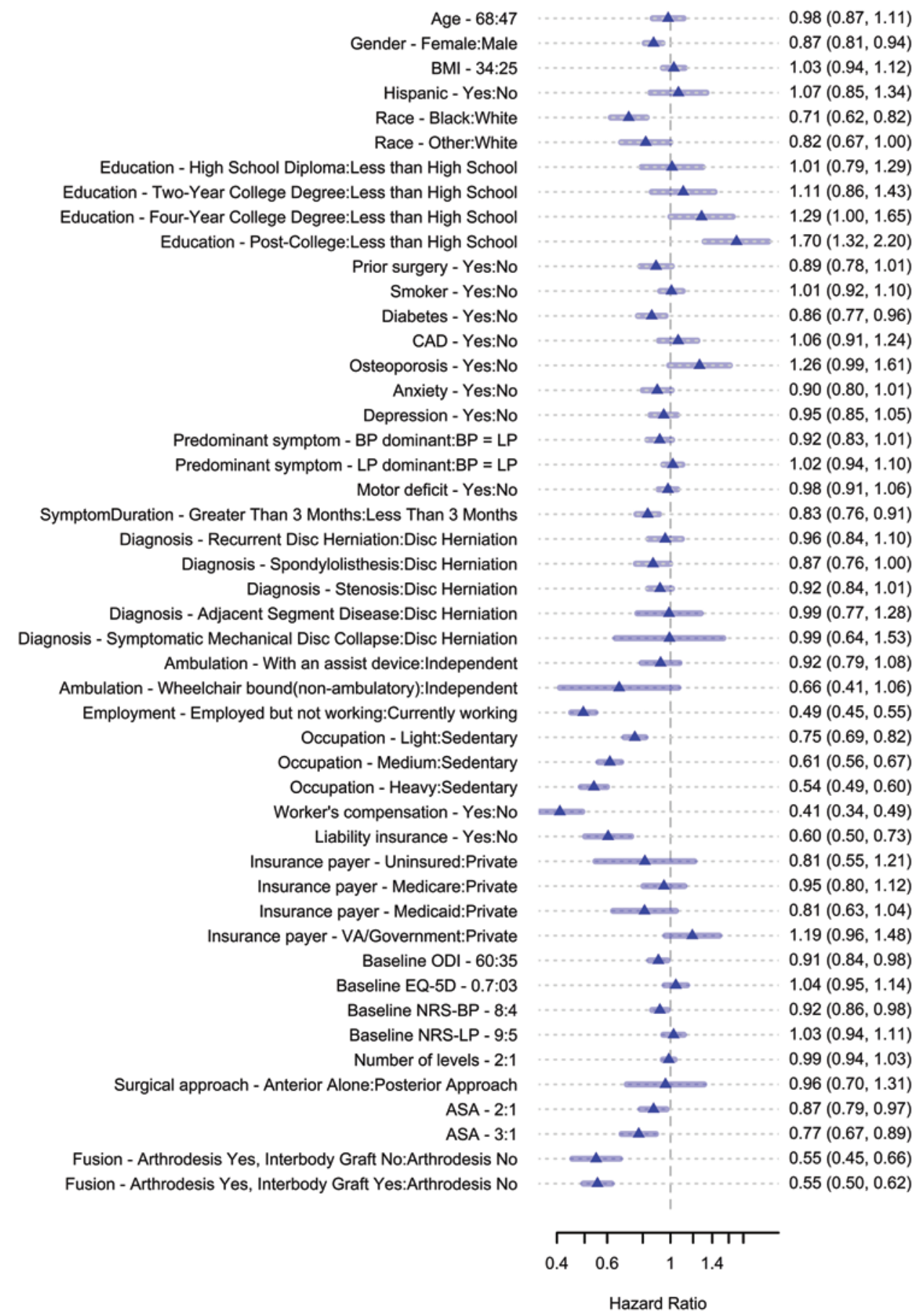

FIG. 1. Adjusted effect of predictors of RTW computed using a multivariable Cox proportional hazards regression model. All the variables in Tables 1 and 2 were included in the model. The HRs for the continuous variables (age, BMI, ODI, EQ-5D, NRS-LP and NRS-BP) in the model were computed based on the upper and lower quartile values. Figure is available in color online only.

spondylolisthesis, adjacent-segment disease, or symptomatic mechanical disc collapse compared with disc herniation. The patients who were preoperatively employed but not actively working at the time of presentation $(\mathrm{p}<0.001)$, those employed in manual labor compared with those with a sedentary occupation ( $\mathrm{p}<0.0001)$, those receiving workers' compensation ( $\mathrm{p}<0.001)$, and those on liability insurance for disability $(\mathrm{p}<0.001)$ had a lower likelihood of returning to work. The patients with higher preoperative NRS-BP scores had a lower likelihood of returning to work within 3 months of surgery $(p=0.0265)$. Similarly, patients with higher preoperative ODI scores had lower likelihood of returning to work within 3 months of surgery $(p=0.0031)$. The likelihood of RTW was also lower for the patients with a higher ASA score $(p=0.0022$; ASA score of 2 vs 1 and a score of 3/4 vs 1) and those undergo- 


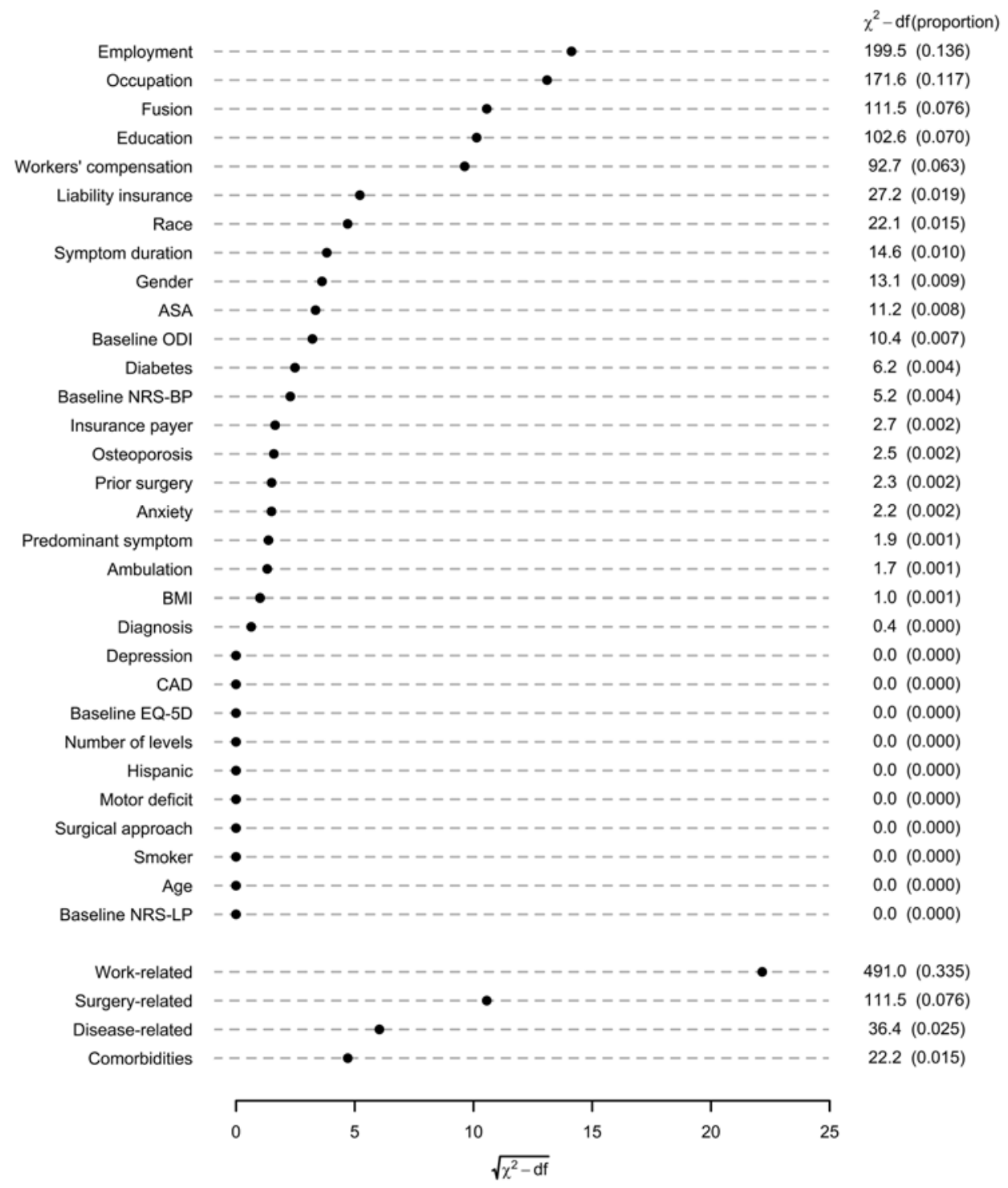

FIG. 2. Importance of predictors, measured by Wald chi-square minus the predictor degree of freedom (df). The relative importance of predictors in the model $\left(\% \chi^{2}-\mathrm{df}\right)$ is listed on the right.

ing fusion compared with those undergoing decompression alone $(\mathrm{p}<0.001)$.

Fig. 2 displays the adjusted importance of each predictive factor included in the model. The most important predictors of RTW 3 months postoperatively were preoperative employment status, manual labor job, fusion, education level, workers' compensation, liability insurance, race, symptom duration, gender, ASA scores, baseline ODI scores, history of diabetes, and baseline NRS-BP scores. The work-related variables (preoperatively employed but not working, occupation type, workers' compensation, and liability insurance), disease-related variables (diagnosis, symptom duration, dominant symptom, motor deficit, ambulation, prior surgery, baseline ODI score, EQ-5D score, and baseline NRS-BP and NRS-LP scores), surgery-related variables (surgical approach, fusion, number of levels fused), and comorbidity variables (ASA scores, diabetes, anxiety, depression, osteoporosis, and CAD) were grouped to determine the pooled effect of these variables on RTW. Figure 3 demonstrates the calibration accuracy for RTW estimates based on the model. The bootstrap-validated c-index was 0.71 , which suggests that our model is useful in predicting RTW after lumbar spine surgery.

Based on the model, we generated 2 hypothetical patients and predicted their probability of returning to work at 6 weeks and 3 months based on the prediction model. The characteristics and predicted probability are listed in Table 3.

\section{Discussion Model}

Predictive models provide individualized risk-adjusted postoperative outcomes, which have the potential to assist providers in setting realistic expectations for patients and families, adjusting modifiable characteristics preopera- 


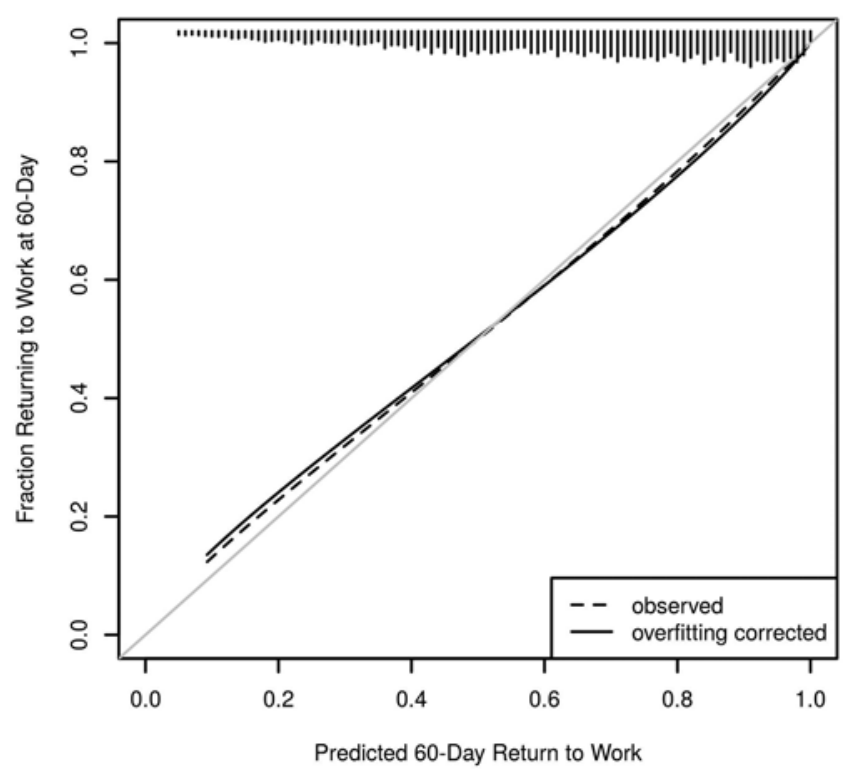

FIG. 3. Bootstrap estimate of calibration accuracy for RTW estimates from the Cox proportional hazards regression model.

tively, engaging patients in shared decision-making, and having a probabilistic discussion regarding postoperative outcomes during preoperative assessment. To use predictive models in the real-world setting, a robust model with high accuracy in predicting the outcomes is needed. Using a prospective, multicenter, longitudinal registry, we introduce a novel model to predict the likelihood of RTW within 3 months of lumbar spine surgery, which demonstrated good discrimination, with a c-index of 0.71 . The most important predictors of RTW at 3 months were preoperative employment status, manual labor job, need for fusion, education level, workers' compensation, liability insurance, race, symptom duration, gender, ASA score, baseline ODI score, history of diabetes, and baseline NRS-BP score.

\section{Work-Related Factors}

Work-related factors contributed the most (33.3\%) to predicting a patient's chance of returning to work. In particular, preoperative work status was the most important predictor of RTW. Those employed preoperatively but not actively working at the time of surgery had a lower likelihood of returning to work than those who were working at the time of surgery. Previous studies have demonstrated similar associations between preoperative employment status and postoperative RTW.2,4,34 Time away from work has a direct negative correlation with RTW. ${ }^{28}$ Anderson et al. have reported that patients who were working at the time of surgery were 10.5 times more likely to be working at follow-up after fusion surgery. ${ }^{4}$ Type of occupation is another important predictor of postoperative RTW. Compared with those employed in sedentary jobs, the patients working in manual labor (heavy labor jobs < medium labor < light labor jobs) had a lower likelihood of returning to work. One might assume that patients employed and not working at the time of surgery had more severe and/or complicated lumbar spine pathologies (e.g., lumbar spondylolisthesis vs herniated lumbar disc), but the presence of such conditions does not fully account for the strong independent influence of work-related factors based on our present predictive model. In any event, the association between occupation, employment status, and RTW is likely multifactorial. Previous sociological models have revealed that multiple factors such as psychological state, job satisfaction, availability of modified duty, physical demand at work, employer-employee relations, litigation issues, income, and social support influence the ability to recover and RTW postoperatively. ${ }^{4,16,30,47,49}$

Active workers' compensation and disability insurance had a negative impact on RTW. Numerous studies have demonstrated that the financial incentives and the adversarial nature of the workers' compensation and liability insurance system may account for worse outcomes and delayed or no RTW. ${ }^{9,12,24,30}$ In our analysis, workers' compensation was a more important predictor for lower likelihood of RTW than liability insurance. Workers' compensation is meant to create a bridge for the injured worker to get back to a level of gainful employment, and liability insurance is a permanent form of compensation. Although both systems are well-intended (i.e., they provide important protections for injured workers), they actually create positive financial incentives for avoiding or delaying RTW, thus influencing this outcome beyond the impact of true functional recovery.

\section{Surgery-Related Factors}

Compared with decompression alone, decompression with fusion has been found to be associated with higher complication rates, longer periods of recovery, and delayed RTW. ${ }^{51,55,56,65}$ In our analysis, the likelihood of RTW at 3 months postoperatively was lower for patients undergoing fusion than those undergoing decompression alone. This finding is not surprising, as patients undergoing fusion often have more severe disability, require longer rehabilitation and recovery periods, and have greater postoperative activity restrictions compared with those undergoing decompression alone. Theoretically, the effect of fusion on outcomes may be diagnosis specific. In our analysis, there was no difference in the RTW outcomes for patients with diagnoses of stenosis, spondylolisthesis, adjacent-segment disease, mechanical disc collapse, and recurrent disc herniation, compared those with a diagnosis of disc herniation. Unfortunately, we do not have adequate numbers of patients within each diagnosis category to determine the true effect of fusion based on diagnosis. As patients continue to be enrolled in the QOD lumbar spine registry, we will ultimately accumulate sufficient data to allow for the development of unique RTW models for each diagnosis. Other surgery-related factors, including number of levels and surgical approach, did not contribute significantly to probability of RTW.

\section{Education Level}

Patients with a higher level of education had greater likelihood of postoperative RTW. Patients with 4-year college and postcollege levels of education were more likely to have desk or nonlaborious jobs, which increased their likelihood to RTW. Patients with a higher educational status are more likely to be engaged in professional ca- 
TABLE 3. The probability of a hypothetical Patient A and Patient B returning to work at 6 weeks and 3 months postoperatively

\begin{tabular}{|c|c|c|}
\hline Variable & Patient A & Patient B \\
\hline Age (yrs) & 35 & 55 \\
\hline BMI & 27 & 35 \\
\hline Gender & Female & Male \\
\hline Hispanic & No & No \\
\hline Race & White & White \\
\hline Education & Less than high school & High school diploma \\
\hline Prior surgery & No & No \\
\hline Smoker & Yes & Yes \\
\hline Diabetes & No & Yes \\
\hline CAD & No & Yes \\
\hline Osteoporosis & No & No \\
\hline Anxiety & Yes & No \\
\hline Depression & Yes & No \\
\hline Dominant symptom & LP dominant & BP dominant \\
\hline Motor deficit & No & No \\
\hline ASA score & 2 & 3 \\
\hline Symptom duration & $>3$ mos & $<3$ mos \\
\hline Diagnosis & Stenosis & Spondylolisthesis \\
\hline No. of surgical levels & 1 & 2 \\
\hline Interbody graft & No & Yes \\
\hline Arthrodesis & No & Yes \\
\hline Approach & Posterior & Posterior \\
\hline Insurance & Private & Medicare \\
\hline Ambulation & Independent & With assistance \\
\hline Occupation & Medium labor job & Heavy labor job \\
\hline Employed and working & Employed but not working & Employed but not working \\
\hline Compensation & Yes & Yes \\
\hline Liability & No & Yes \\
\hline Baseline ODI score & 60 & 80 \\
\hline Baseline EQ-5D score & 0.7 & 0.3 \\
\hline Baseline NRS-BP score & 7 & 9 \\
\hline Baseline NRS-LP score & 9 & 8 \\
\hline Probability of RTW at 6 wks $(95 \% \mathrm{Cl})$ & $69.1 \%(56.4 \%-81.0 \%)$ & $32.4 \%(17.6 \%-33.5 \%)$ \\
\hline Probability of RTW at 3 mos $(95 \% \mathrm{Cl})$ & $99.8 \%(98.7 \%-99.9 \%)$ & $90.9 \%(63.7 \%-88.1 \%)$ \\
\hline
\end{tabular}

reers, which theoretically makes RTW easier due to less demanding physical work. ${ }^{68}$ Furthermore, a higher education level may also allow for a better understanding of disease processes, which may result in these patients forming more realistic postoperative expectations, being more treatment compliant, and achieving better recoveries. ${ }^{40,53}$

\section{Diagnosis-Related Factors}

Patients with longer preoperative symptom duration (> 3 months) had a lower likelihood of returning to work. Grøvle et al. have reported that duration of sciatica more than 3 months in patients with disc herniation is associated with longer time to RTW. ${ }^{29}$ Radcliff et al.$^{57}$ have reported that the patients with stenosis and symptom duration less than 12 months have significantly better outcomes; how- ever, in patients with spondylolisthesis, the preoperative symptom duration was not associated with outcomes. ${ }^{57}$ Patients with greater baseline disability (i.e., high ODI scores) and back pain were less likely to RTW at 3 months. Previous studies have demonstrated that the patients who start out with worse disability and pain scores are less likely to RTW postoperatively. The Maine Lumbar Spine Study data indicated that less-severe low-back pain at presentation was associated with higher RTW rates at 4 years after lumbar discectomy. ${ }^{8}$ Patients with poor functional status preoperatively have higher needs for postoperative rehabilitation, which prolongs the recovery period. This finding highlights the importance of adjusting for varying degrees of symptom duration, baseline disability, and pain when assessing RTW outcomes. 


\section{Patient Demographic Factors and Comorbidities}

The demographic factors female gender and African American race were associated with lower likelihood of returning to work. A number of studies have reported the effect of gender and racial differences on outcomes and RTW after lumbar spine surgery. ${ }^{18,37,59,61}$ The racial disparity in returning to work can be partly explained by the barriers in education, attitudes toward health care, and economic status. ${ }^{3,36,61}$ The issue of racial disparity and association with outcomes and RTW, however, is multidimensional and complex; further studies focused on this parameter are clearly needed.

Consistent with our findings, several previous studies have reported that preoperative comorbidities are significantly associated with delayed postoperative recovery and hence are associated with a lower likelihood of returning to work. ${ }^{10,39,44,64}$ Our model suggests that preoperative history of diabetes and ASA scores in particular should be accounted for when evaluating the probability of 3-month postoperative RTW outcome.

\section{Study Limitations and Strengths}

The c-index of model performance was 0.71 , which can be considered a "good" discrimination index. One intrinsic limitation of predictive models is the discrete number of variables that are inputted into their creation. In the present analysis, we included 28 patient-specific and surgery-specific variables collected as a part of the multicenter QOD registry. It is possible that variables not collected and therefore not accounted for in this analysis will play a significant role in an RTW outcome. Previously reported variables that contribute to RTW missing from our registry include the following: marital status and family support, preoperative willingness of returning to work, and working conditions, including employer-employee relationship and work-related stress. Such missing data could affect the performance of statistical models in discriminating accurately between observed and predicted outcomes.

"Returning to work" was defined as any RTW within 3 months after surgery. It is possible that patients did not RTW at full preoperative capacity, which is not captured in the present analysis. Future analyses will include a more granular evaluation of actual work capacity, as well as extending the follow-up duration of this outcome to 1 year, particularly in patients undergoing more invasive procedures such as fusion surgery. With exponentially increasing numbers of patients enrolled in the QOD registry, and with further refinement of variables collected, we will be able to continuously update our predictive model to increase its performance and accuracy. Furthermore, discovery of potential interactions between already collected variables will further improve performance and accuracy.

In spite of these potential limitations, our current novel, risk-adjusted predictive model for RTW provides significant value as a starting point for patient-level predictive analytics to guide shared decision-making with the goal of optimizing outcomes at the individual patient and population levels. This value is derived from 2 major sources: first, this national project has, by design, included a diverse range of practice and patient types, which allows for a true representative sampling of patients undergoing elective lumbar spinal surgery. Specifically, the patients included in the QOD registry are enrolled from 74 centers across the US representing a roughly equal number of academic and private practices, and including small, medium, and large centers in both rural and metropolitan settings. $5,27,50$ These structural features enhance the generalizability of registry results, which is to say, the relevance of the results to a broad range of patients undergoing spine surgery. Second, as has been mentioned above, even this preliminary model exhibits good discrimination, and it can therefore be used in its present form to generate the probabilities of returning to work within 3 months after surgery in a fashion that can be meaningful to individual patients, care providers, and other health care stakeholders.

As calculations such as those involved in deriving individual RTW probabilities from this present model can be difficult to perform in a real-world clinic setting, we have created an online application that can be more easily used in the spine clinic to predict 3-month RTW (http:// statcomp2.vanderbilt.edu:37212/app_0/). We are currently testing a variety of health information technology models to further simplify the use of this predictive model in the clinic, with the objective of embedding this methodology in daily practice workflows. By enabling patient-specific probabilistic counseling at the point of care, we seek to facilitate the involvement of all stakeholders in true shared decision-making which, among other potential benefits, can help set appropriate expectations prior to surgery (with the potential to improve patient satisfaction), modify correctable factors that could help improve the potential for RTW, and possibly reduce health care expenditures in situations in which surgical care is deemed unlikely to achieve satisfactory outcomes. Furthermore, outcome prediction modeling can be used by self-insured companies and workers' compensation groups to identify the patients who will RTW and those who will not within 3 months of surgery.

\section{Conclusions}

We present a novel predictive model for the probability of returning to work after lumbar spine surgery. Spine care providers can use this model to educate patients and encourage them in shared decision-making regarding the RTW outcome. This evidence-based decision support will result in better communication between patients and clinicians and improve postoperative recovery expectations, which will ultimately increase the likelihood of a positive RTW trajectory.

\section{Acknowledgments}

This work was supported in part through a grant from the Neurosurgery Research and Education Foundation (NREF).

\section{Appendix}

\section{Quality and Outcomes Database (QOD) Vanguard Sites}

Anthony L. Asher, MD, ${ }^{1}$ Matthew J. McGirt, MD, ${ }^{1}$ Clinton J. Devin, MD, ${ }^{2}$ Joseph S. Cheng, MD, ${ }^{2}$ Kevin T. Foley, MD, ${ }^{3}$ Jeffrey M. Sorenson, MD, ${ }^{3}$ John J. Knightly, MD, ${ }^{4}$ Steven D. Glassman, 
MD, ${ }^{5}$ Thomas B. Briggs, MD, ${ }^{6}$ Adam Kremer, MD, ${ }^{7}$ Wesley E. Griffitt, MD, ${ }^{8}$ Noam Y. Stadlan, MD, ${ }^{9}$ Thomas W. Grahm, MD, ${ }^{10}$ Meic H. Schmidt, MD, ${ }^{11}$ Praveen Mummaneni, MD, ${ }^{12}$ and Mark E. Shaffrey, MD.13

${ }^{1}$ Department of Neurological Surgery, Carolina Neurosurgery and Spine Associates, and Neurological Institute, Carolinas Healthcare System, Charlotte, North Carolina; ${ }^{2}$ Department of Orthopedic Surgery and Neurosurgery, Vanderbilt Spine Center, Vanderbilt University Medical Center, Nashville, Tennessee; ${ }^{3}$ Department of Neurosurgery, University of Tennessee Health Sciences Center, Semmes-Murphey Neurologic \& Spine Institute, Memphis, Tennessee; ${ }^{4}$ Department of Neurosurgery, Atlantic Neurosurgical Specialists, Morristown, New Jersey; ${ }^{5}$ Department of Orthopedic Surgery, University of Louisville, and the Norton Leatherman Spine Center, Louisville, Kentucky; ${ }^{6}$ Springfield Neurologic and Spine Institute, Springfield, Missouri; ${ }^{7}$ Department of Neurosurgery, Brain and Spine Center, Holland, Michigan; ${ }^{8}$ Department of Neurosurgery, Bay Care Clinic Neurological, Green Bay, Wisconsin; ${ }^{9}$ Department of Neurosurgery, North Shore University Health System, Skokie, Illinois; ${ }^{10}$ Department of Surgery, East Texas Medical Center, Tyler Neurosurgical, Tyler, Texas; ${ }^{11}$ Department of Neurosurgery, University of Utah, Salt Lake City, Utah; ${ }^{12}$ Department of Neurological Surgery, University of California, San Francisco, California; and ${ }^{13}$ Department of Neurosurgery, University of Virginia Medical Center, Charlottesville, Virginia.

\section{References}

1. Aalto TJ, Malmivaara A, Kovacs F, Herno A, Alen M, Salmi L, et al: Preoperative predictors for postoperative clinical outcome in lumbar spinal stenosis: systematic review. Spine (Phila Pa 1976) 31:E648-E663, 2006

2. Anderson JT, Haas AR, Percy R, Woods ST, Ahn UM, Ahn NU: Return to work after diskogenic fusion in workers' compensation subjects. Orthopedics 38:e1065-e1072, 2015

3. Anderson NB, Bulatao RA, Cohen B (eds): Critical Perspectives on Racial and Ethnic Differences in Health in Late Life. Washington, DC: National Academies Press, 2004

4. Anderson PA, Schwaegler PE, Cizek D, Leverson G: Work status as a predictor of surgical outcome of discogenic low back pain. Spine (Phila Pa 1976) 31:2510-2515, 2006

5. Asher AL, McCormick PC, Selden NR, Ghogawala Z, McGirt MJ: The National Neurosurgery Quality and Outcomes Database and NeuroPoint Alliance: rationale, development, and implementation. Neurosurg Focus 34(1):E2, 2013

6. Asher AL, McGirt MJ, Glassman SD, Groman R, Resnick DK, Mehrlich M, et al: Regulatory considerations for prospective patient care registries: lessons learned from the National Neurosurgery Quality and Outcomes Database. Neurosurg Focus 34(1):E5, 2013

7. Asher AL, Speroff T, Dittus RS, Parker SL, Davies JM, Selden N, et al: The National Neurosurgery Quality and Outcomes Database (N2QOD): a collaborative North American outcomes registry to advance value-based spine care. Spine (Phila Pa 1976) 39 (22 Suppl 1):S106-S116, 2014

8. Atlas SJ, Chang Y, Keller RB, Singer DE, Wu YA, Deyo RA: The impact of disability compensation on long-term treatment outcomes of patients with sciatica due to a lumbar disc herniation. Spine (Phila Pa 1976) 31:3061-3069, 2006

9. Atlas SJ, Tosteson TD, Blood EA, Skinner JS, Pransky GS, Weinstein JN: The impact of workers' compensation on outcomes of surgical and nonoperative therapy for patients with a lumbar disc herniation: SPORT. Spine (Phila Pa 1976) 35:89-97, 2010

10. Bekelis K, Desai A, Bakhoum SF, Missios S: A predictive model of complications after spine surgery: the National Surgical Quality Improvement Program (NSQIP) 2005-2010. Spine J 14:1247-1255, 2014
11. Bennion SK: Overcoming barriers for a successful return to work. Prof Case Manag 13:241-243, 2008

12. Berecki-Gisolf J, Clay FJ, Collie A, McClure RJ: Predictors of sustained return to work after work-related injury or disease: insights from workers' compensation claims records. J Occup Rehabil 22:283-291, 2012

13. Charles C, Gafni A, Whelan T: Shared decision-making in the medical encounter: what does it mean? (or it takes at least two to tango). Soc Sci Med 44:681-692, 1997

14. Chotai S, Parker SL, Sivaganesan A, Sielatycki JA, Asher AL, McGirt MJ, et al: Effect of complications within 90 days on patient-reported outcomes 3 months and 12 months following elective surgery for lumbar degenerative disease. Neurosurg Focus 39(6): E8, 2015

15. Chou R, Shekelle P: Will this patient develop persistent disabling low back pain? JAMA 303:1295-1302, 2010

16. Cole DC, Ibrahim S, Shannon HS, Scott FE, Eyles J: Work and life stressors and psychological distress in the Canadian working population: a structural equation modelling approach to analysis of the 1994 National Population Health Survey. Chronic Dis Can 23:91-99, 2002

17. Copeland B: Surgical versus nonsurgical treatment for back pain. N Engl J Med 357:1255-1256, 2007

18. Daumit GL, Hermann JA, Coresh J, Powe NR: Use of cardiovascular procedures among black persons and white persons: a 7-year nationwide study in patients with renal disease. Ann Intern Med 130:173-182, 1999

19. Department of Health and Human Services: Protection of human subjects; reports of the President's Commission for the Study of Ethical Problems in Medicine and Biomedical and Behavioral Research. Fed Regist 48:34408-34412, 1983

20. Deyo RA, Tsui-Wu YJ: Descriptive epidemiology of lowback pain and its related medical care in the United States. Spine (Phila Pa 1976) 12:264-268, 1987

21. EuroQol Group: EuroQol-a new facility for the measurement of health-related quality of life. Health Policy 16:199208, 1990

22. Fairbank JC: Oswestry disability index. J Neurosurg Spine 20:239-241, 2014

23. Fairbank JC, Pynsent PB: The Oswestry Disability Index. Spine (Phila Pa 1976) 25:2940-2952, 2000

24. Franklin GM, Haug J, Heyer NJ, McKeefrey SP, Picciano JF: Outcome of lumbar fusion in Washington State workers' compensation. Spine (Phila Pa 1976) 19:1897-1904, 1994

25. Fritzell P, Hägg O, Nordwall A: Complications in lumbar fusion surgery for chronic low back pain: comparison of three surgical techniques used in a prospective randomized study. A report from the Swedish Lumbar Spine Study Group. Eur Spine J 12:178-189, 2003

26. Frymoyer JW, Pope MH, Clements JH, Wilder DG, MacPherson B, Ashikaga T: Risk factors in low-back pain. An epidemiological survey. J Bone Joint Surg Am 65:213218, 1983

27. Ghogawala Z, Shaffrey CI, Asher AL, Heary RF, Logvinenko T, Malhotra NR, et al: The efficacy of lumbar discectomy and single-level fusion for spondylolisthesis: results from the NeuroPoint-SD registry: clinical article. J Neurosurg Spine 19:555-563, 2013

28. Graver V, Ljunggren AE, Loeb M, Haaland AK, Lie H, Magnaes B: Background variables (medical history, anthropometric and biological factors) in relation to the outcome of lumbar disc surgery. Scand J Rehabil Med 30:221-225, 1998

29. Grøvle L, Haugen AJ, Keller A, Ntvig B, Brox JI, Grotle M: Prognostic factors for return to work in patients with sciatica. Spine J 13:1849-1857, 2013

30. Gum JL, Glassman SD, Carreon LY: Is type of compensation a predictor of outcome after lumbar fusion? Spine (Phila Pa 1976) 38:443-448, 2013

31. Harrell FE Jr, Califf RM, Pryor DB, Lee KL, Rosati RA: 
Evaluating the yield of medical tests. JAMA 247:2543-2546, 1982

32. Harrell FE Jr, Lee KL, Califf RM, Pryor DB, Rosati RA: Regression modelling strategies for improved prognostic prediction. Stat Med 3:143-152, 1984

33. Harris PA, Taylor R, Thielke R, Payne J, Gonzalez N, Conde JG: Research electronic data capture (REDCap) - a metadata-driven methodology and workflow process for providing translational research informatics support. J Biomed Inform 42:377-381, 2009

34. Hodges SD, Humphreys SC, Eck JC, Covington LA, Harrom $\mathrm{H}$ : Predicting factors of successful recovery from lumbar spine surgery among workers' compensation patients. J Am Osteopath Assoc 101:78-83, 2001

35. Johansson AC, Ohrvik J, Soderlund A: Associations among pain, disability and psychosocial factors and the predictive value of expectations on returning to work in patients who undergo lumbar disc surgery. Eur Spine J 25:296-303, 2016

36. Kahn JR, Fazio EM: Economic status over the life course and racial disparities in health. J Gerontol B Psychol Sci Soc Sci 60:76-84, 2005

37. Katz JN: Patient preferences and health disparities. JAMA 286:1506-1509, 2001

38. Kim BD, Smith TR, Lim S, Cybulski GR, Kim JY: Predictors of unplanned readmission in patients undergoing lumbar decompression: multi-institutional analysis of 7016 patients. J Neurosurg Spine 20:606-616, 2014

39. Kim CH, Chung CK, Shin S, Choi BR, Kim MJ, Park BJ, et al: The relationship between diabetes and the reoperation rate after lumbar spinal surgery: a nationwide cohort study. Spine J 15:866-874, 2015

40. Laaksonen M, Talala K, Martelin T, Rahkonen O, Roos E, Helakorpi S, et al: Health behaviours as explanations for educational level differences in cardiovascular and all-cause mortality: a follow-up of 60000 men and women over 23 years. Eur J Public Health 18:38-43, 2008

41. Langley GB, Sheppeard H: The visual analogue scale: its use in pain measurement. Rheumatol Int 5:145-148, 1985

42. Luo X, Pietrobon R, Sun SX, Liu GG, Hey L: Estimates and patterns of direct health care expenditures among individuals with back pain in the United States. Spine (Phila Pa 1976) 29:79-86, 2004

43. Maghout Juratli S, Franklin GM, Mirza SK, Wickizer TM, Fulton-Kehoe D: Lumbar fusion outcomes in Washington State workers' compensation. Spine (Phila Pa 1976) 31:2715-2723, 2006

44. Mannion AF, Fekete TF, Porchet F, Haschtmann D, Jeszenszky D, Kleinstück FS: The influence of comorbidity on the risks and benefits of spine surgery for degenerative lumbar disorders. Eur Spine J 23 (Suppl 1):S66-S71, 2014

45. Martin BI, Deyo RA, Mirza SK, Turner JA, Comstock BA, Hollingworth W, et al: Expenditures and health status among adults with back and neck problems. JAMA 299:656-664, 2008

46. Martin BI, Mirza SK, Comstock BA, Gray DT, Kreuter W, Deyo RA: Reoperation rates following lumbar spine surgery and the influence of spinal fusion procedures. Spine (Phila Pa 1976) 32:382-387, 2007

47. Maxwell TD, Gatchel RJ, Mayer TG: Cognitive predictors of depression in chronic low back pain: toward an inclusive model. J Behav Med 21:131-143, 1998

48. McGirt MJ, Speroff T, Dittus RS, Harrell FE Jr, Asher AL: The National Neurosurgery Quality and Outcomes Database $\left(\mathrm{N}^{2} \mathrm{QOD}\right)$ : general overview and pilot-year project description. Neurosurg Focus 34(1):E6, 2013

49. Mroz TE, Norvell DC, Ecker E, Gruenberg M, Dailey A, Brodke DS: Fusion versus nonoperative management for chronic low back pain: do sociodemographic factors affect outcome? Spine (Phila Pa 1976) 36 (21 Suppl):S75-S86, 2011
50. Mummaneni PV, Whitmore RG, Curran JN, Ziewacz JE, Wadhwa R, Shaffrey CI, et al: Cost-effectiveness of lumbar discectomy and single-level fusion for spondylolisthesis: experience with the NeuroPoint-SD registry. Neurosurg Focus 36(6):E3, 2014

51. Nguyen TH, Randolph DC, Talmage J, Succop P, Travis R: Long-term outcomes of lumbar fusion among workers' compensation subjects: a historical cohort study. Spine (Phila Pa 1976) 36:320-331, 2011

52. North RB, Campbell JN, James CS, Conover-Walker MK, Wang H, Piantadosi S, et al: Failed back surgery syndrome: 5 -year follow-up in 102 patients undergoing repeated operation. Neurosurgery 28:685-691, 1991

53. Olson PR, Lurie JD, Frymoyer J, Walsh T, Zhao W, Morgan TS, et al: Lumbar disc herniation in the Spine Patient Outcomes Research Trial: does educational attainment impact outcome? Spine (Phila Pa 1976) 36:2324-2332, 2011

54. Parker SL, Godil SS, Zuckerman SL, Mendenhall SK, Devin CJ, McGirt MJ: Extent of preoperative depression is associated with return to work after lumbar fusion for spondylolisthesis. World Neurosurg 83:608-613, 2015

55. Parker SL, Lerner J, McGirt MJ: Effect of minimally invasive technique on return to work and narcotic use following transforaminal lumbar inter-body fusion: a review. Prof Case Manag 17:229-235, 2012

56. Puolakka K, Ylinen J, Neva MH, Kautiainen H, Häkkinen A: Risk factors for back pain-related loss of working time after surgery for lumbar disc herniation: a 5-year follow-up study. Eur Spine J 17:386-392, 2008

57. Radcliff KE, Rihn J, Hilibrand A, DiIorio T, Tosteson T, Lurie JD, et al: Does the duration of symptoms in patients with spinal stenosis and degenerative spondylolisthesis affect outcomes?: analysis of the Spine Outcomes Research Trial. Spine (Phila Pa 1976) 36:2197-2210, 2011

58. Ragab A, Deshazo RD: Management of back pain in patients with previous back surgery. Am J Med 121:272-278, 2008

59. Schoenfeld AJ, Sieg RN, Li G, Bader JO, Belmont PJ Jr, Bono CM: Outcomes after spine surgery among racial/ethnic minorities: a meta-analysis of the literature. Spine J 11:381388,2011

60. Sherman J, Cauthen J, Schoenberg D, Burns M, Reaven NL, Griffith SL: Economic impact of improving outcomes of lumbar discectomy. Spine J 10:108-116, 2010

61. Skinner J, Weinstein JN, Sporer SM, Wennberg JE: Racial, ethnic, and geographic disparities in rates of knee arthroplasty among Medicare patients. N Engl J Med 349:1350-1359, 2003

62. Spengler DM: Lumbar discectomy. Results with limited disc excision and selective foraminotomy. Spine (Phila Pa 1976) 7:604-607, 1982

63. Stewart WF, Ricci JA, Chee E, Morganstein D, Lipton R: Lost productive time and cost due to common pain conditions in the US workforce. JAMA 290:2443-2454, 2003

64. Takahashi S, Suzuki A, Toyoda H, Terai H, Dohzono S, Yamada K, et al: Characteristics of diabetes associated with poor improvements in clinical outcomes after lumbar spine surgery. Spine (Phila Pa 1976) 38:516-522, 2013

65. Tosteson AN, Skinner JS, Tosteson TD, Lurie JD, Andersson GB, Berven S, et al: The cost effectiveness of surgical versus nonoperative treatment for lumbar disc herniation over two years: evidence from the Spine Patient Outcomes Research Trial (SPORT). Spine (Phila Pa 1976) 33:2108-2115, 2008

66. Waterman BR, Belmont PJ Jr, Schoenfeld AJ: Low back pain in the United States: incidence and risk factors for presentation in the emergency setting. Spine (Phila Pa 1976) J 12:63-70, 2012

67. Weinstein JN, Tosteson TD, Lurie JD, Tosteson AN, Hanscom B, Skinner JS, et al: Surgical vs nonoperative treatment for lumbar disk herniation: the Spine Patient Outcomes Re- 
search Trial (SPORT): a randomized trial. JAMA 296:24412450, 2006

68. Zieger M, Luppa M, Meisel HJ, Günther L, Winkler D, Toussaint R, et al: The impact of psychiatric comorbidity on the return to work in patients undergoing herniated disc surgery. J Occup Rehabil 21:54-65, 2011

\section{Disclosures}

Dr. Devin has served as a consultant to Exparel and Medtronic, and has received support of non-study-related clinical or research effort from Stryker Spine. Dr. Shaffrey has served as a consultant to Medtronic, NuVasive, K2M, and Zimmer-Biomet; has direct stock ownership in NuVasive; and is a patent holder for Medtronic, NuVasive, and Zimmer-Biomet. Dr. Foley has served as a consultant to Medtronic; has direct stock ownership in BioD, Discgenics, Medtronic, NuVasive, Spinewave, and TrueVision; and is a patent holder for Discgenics, Medtronic, and NuVasive.

\section{Author Contributions}

Conception and design: Asher, Devin, Chotai, McGirt. Acquisi- tion of data: Chotai, Nian. Analysis and interpretation of data: Chotai, Nian, Harrell. Drafting the article: Asher, Devin, Chotai. Critically revising the article: Asher, Devin, Archer, Chotai, Parker, Speroff, McGirt. Reviewed submitted version of manuscript: Asher, Devin, Archer, Chotai, Parker, Bydon, Speroff, Dittus, Shaffrey, Foley, McGirt. Statistical analysis: Nian, Harrell. Administrative/technical/material support: Chotai, Dittus, Philips. Study supervision: Asher, Devin, Bydon, McGirt.

\section{Supplemental Information \\ Companion Papers}

McGirt MJ, Bydon M, Archer KR, Devin CJ, Chotai S, Parker SL, et al: An analysis from the Quality Outcomes Database, Part 1. Disability, quality of life, and pain outcomes following lumbar spine surgery: predicting likely individual patient outcomes for shared decision-making. DOI: 10.3171/2016.11.SPINE16526.

\section{Correspondence}

Anthony L. Asher, Department of Neurological Surgery, Carolina Neurosurgery and Spine Associates, 225 Baldwin Rd., Charlotte, NC 28204. email: tony.asher@cnsa.com. 